\title{
Термоэлектрическая эффективность и квантовая подвижность дырок в монокристаллах теллурида сурьмы, легированных медью
}

\author{
(C) В.А. Кульбачинский ${ }^{1,2,3}$, В.Г. Кытин ${ }^{1}$, А.С. Апрелева ${ }^{1}$, Е.А. Константинова ${ }^{1}$ \\ ${ }^{1}$ Московский государственный университет им. М.В. Ломоносова \\ (физический Факультет, кафедра фризики низких температур и сверхпроводимости), \\ 119991 ГСП-1, Москва, Россия \\ ${ }^{2}$ Московский физико-технический институт, \\ 141700 Долгопрудный, Московская область, Россия \\ ${ }^{3}$ Национальный исследовательский центр „Курчатовский институт“, \\ 123182 Москва, Россия \\ E-mail: kulb@mig.phys.msu.ru
}

Поступила в Редакцию 12 августа 2021 г.

В окончательной редакции 28 августа 2021 г.

Принята к публикации 28 августа 2021 г.

Сообщаются результаты исследования термоэлектрических свойств в интервале температур $77<T<350 \mathrm{~K}$ монокристаллических образцов $\mathrm{Sb}_{2-x} \mathrm{Cu}_{x} \mathrm{Te}_{3}(0 \leq x \leq 0.10)$, синтезированных методом Бриджмена. Оказалось, что концентрация дырок и проводимость сильно возрастают, а коэффициент Зеебека незначительно уменьшается при легировании $\mathrm{Sb}_{2} \mathrm{Te}_{3}$ медью. Теплопроводность образцов, легированных $\mathrm{Cu}$, была несколько выше, чем у исходного $\mathrm{Sb}_{2} \mathrm{Te}_{3}$. В результате термоэлектрическая эффективность $\mathrm{ZT}$ возрастает с увеличением содержания Сu при $T>300 \mathrm{~K}$. Кроме этого приводятся результаты измерений квантовой подвижности дырок $\mu_{q}$ из данных по эффекту Шубникова-де Гааза как в монокристаллах $\mathrm{Sb}_{2-x} \mathrm{Cu}_{x} \mathrm{Te}_{3}(0 \leq x \leq 0.10)$, так и в монокристаллах $\mathrm{Sb}_{2-x} \mathrm{Sn}_{x} \mathrm{Te}_{3}(0 \leq x \leq 0.01) ; \mathrm{Sb}_{2-x} \mathrm{Tl}_{x} \mathrm{Te}_{3}(0 \leq x \leq 0.05)$. Измерения ЭПР показывают, что атомы меди в исследованных образцах, скорее всего, находятся в бесспиновом состоянии $\mathrm{Cu}^{+1}$.

Ключевые слова: термоэлектрическая эффективность, теллурид сурьмы, электронный парамагнитный резонанс, эффект Шубникова-де Гааза.

DOI: $10.21883 /$ FTP.2021.12.51696.11

\section{1. Введение}

Термоэлектрические материалы $\mathrm{Bi}_{2} \mathrm{Te}_{3}$ и $\mathrm{Sb}_{2} \mathrm{Te}_{3}$ широко применяются в термоэлектрических устройствах при комнатных температурах. $\mathrm{Sb}_{2} \mathrm{Te}_{3}$ является известным термоэлектрическим материалом [1]. Однако эффективность термоэлектрического материала ограничена его низким значением безразмерного параметра

$$
\mathrm{ZT}=\sigma \mathrm{S}^{2} K / \kappa
$$

где $\sigma-$ проводимость, $\mathrm{S}-$ коэффициент Зеебека, $\kappa$ - теплопроводность. Эффективным методом тонкой подгонки транспортных свойств, а именно $\sigma, \mathrm{S}$ и $\kappa$, является легирование $\mathrm{Sb}_{2} \mathrm{Te}_{3}$ [2-4]. $\mathrm{Sb}_{2} \mathrm{Te}_{3}$ - слоистый кристалл, имеющий ромбоэдрическую структуру и пространственную группу симметрии $R \overline{3} m-D_{3 d}^{5}$. Кристаллическая решетка образована периодически упорядоченными слоями, лежащими в плоскости, перпендикулярной оси $\mathrm{C}_{3}$. Каждый слой состоит из пяти атомных плоскостей (квинтетов), образующих следующую последовательность: Te1-Sb-Te2-Sb-Te1. Здесь Те1 и Te2 обозначают атомы Те в различных положениях. Химическая связь внутри квинтетов является ковалентноионной. Между квинтетами существует сравнительно большое расстояние и слабая связь, создаваемая силами ван-дер-Ваальса. Это отвечает за анизотропию прово- димости, термоэдс и другие свойства монокристаллов. Кристаллы $\mathrm{Sb}_{2} \mathrm{Te}_{3}$ имеют высокую концентрацию дырок из-за наличия большого количества заряженных точечных дефектов. Поскольку антиструктурные дефекты заряжены отрицательно, $\mathrm{Sb}_{2} \mathrm{Te}_{3}$, выращенный в стехиометрических условиях, всегда обладает проводимостью $p$-типа и имеет высокую концентрацию дырок. Слабая полярность связей $\mathrm{Sb}-\mathrm{Te}$ способствует образованию антиструктурных дефектов. Изменение полярности связей, вызванное легированием или смещением стехиометрии, приводит к изменению концентрации антиструктурных дефектов. Если предположить, что заряд антиструктурных дефектов компенсируется дырками, то любое изменение концентрации антиструктурных дефектов будет соответствовать изменению концентрации дырок. Легирование $\mathrm{Sb}_{2} \mathrm{Te}_{3}$ оказывает сильное влияние на концентрацию точечных дефектов и, следовательно, на концентрацию носителей заряда. Следовательно, легирование элементами определенных групп Периодической таблицы элементов им. Д.И. Менделеева может иметь донорный или акцепторный эффект не в зависимости от номера группы, а в результате влияния легирующего элемента на полярность связи.

В данной работе мы исследуем влияние легирования $\mathrm{Cu}$ на термоэлектрические свойства монокристаллов $p-\mathrm{Sb}_{2-x} \mathrm{Cu}_{x} \mathrm{Te}_{3}$ в интервале температур 77-350 K. 
Кроме этого приводятся результаты измерений квантовой подвижности дырок $\mu_{q}$ из данных по эффекту Шубникова-де Гааза (ШдГ) как в монокристаллах $\mathrm{Sb}_{2-x} \mathrm{Cu}_{x} \mathrm{Te}_{3} \quad(0 \leq x \leq 0.10)$, так и в монокристаллах $\mathrm{Sb}_{2-x} \mathrm{Sn}_{x} \mathrm{Te}_{3}(0 \leq x \leq 0.01) ; \mathrm{Sb}_{2-x} \mathrm{Tl}_{x} \mathrm{Te}_{3}(0 \leq x \leq 0.05)$.

\section{2. Образцы и методика эксперимента}

В работе исследованы монокристаллические образцы $p$-типа теллурида сурьмы - $\mathrm{Sb}_{2} \mathrm{Te}_{3}$, легированные медью, выращенные методом Бриджмена из поликристаллических материалов. Сначала мы синтезировали поликристаллические образцы из 99.999\% чистых элементов в стехиометрическом соотношении в кварцевой ампуле. В стехиометрический поликристалл для легирования добавлялась медь, чтобы впоследствии образцы образцы имели состав $\mathrm{Sb}_{2-x} \mathrm{Cu}_{x} \mathrm{Te}_{3}(x=0,0.01,0.07$, $0.10)$. После приготовления поликристалла необходимого состава выращивались монокристаллы. Выращенные монокристаллы освобождались из кварцевой ампулы и кололись в жидком азоте перпендикулярно оси $C_{3}$, которая после выращивания всегда была перпендикулярна продольной оси слитка. Образцы для измерений в форме параллелепипеда со средними размерами $1 \times 1 \times 5$ мм с длинной осью, направленной вдоль оси $\mathrm{C}_{2}$, были вырезаны с помощью электроэрозионного метода. Токовые и потенциальные выводы к образцу делались из медной проволоки диаметром 30 мкм, в качестве припоя использовался сплав $\mathrm{Bi}+4 \% \mathrm{Sb}$. Исследовались монокристаллические образцы $p$-типа теллурида сурьмы, легированного медью. Измерения электронного парамагнитного резонанса были проведены для получения информации о зарядовом состоянии атомов $\mathrm{Cu}$ в $\mathrm{Sb}_{2-x} \mathrm{Cu}_{x} \mathrm{Te}_{3}$. Как правило, в химических соединениях медь может находиться в состоянии $\mathrm{Cu}^{+1}$ или $\mathrm{Cu}^{+2}$. Ионы $\mathrm{Cu}^{+1}$ имеют нулевой спин, в то время как ионы $\mathrm{Cu}^{+2}$ имеют спин $1 / 2$ и соответствующий магнитный момент. Для измерений ЭПР были подготовлены образцы с площадью $\sim 4 \mathrm{Mм}^{2}$ и толщиной $\sim 0.1$ мкм. Измерения ЭПР проводились с использованием спектрометра Bruecker E500 X-диапазона. Микроволновая частота была близка к 9ГГц. При такой частоте глубина скин-слоя близка к 2 мкм для кристаллов с 2 ат\% $\mathrm{Cu}$, что превышает толщину чешуек, приготовленных для измерения ЭПР. Для получения спектров ЭПР пять образцов с различным содержанием меди с описанными выше размерами были вставлены в резонатор спектрометра.

\section{3. Результаты измерений и их обсуждение}

\section{1. ЭПР}

Сигнал ЭПР не был обнаружен для всех исследованных образцов. Общий объем, который может вносить вклад в сигнал ЭПР, близок к 0.07 мм $^{3}$ для образца с содержанием $10 \% \mathrm{Cu}$, при условии, что микроволновое излучение проникает в каждый образец с обеих сторон. Для образца с 2 ат\% $\mathrm{Cu}$ в этом объеме содержится $\sim 1.7 \cdot 10^{18}$ ионов меди. Чувствительность используемого спектрометра ЭПР составляет $10^{11}$ спин/Гс. Это означает, что либо доля ионов $\mathrm{Cu}^{+2}$ очень мала, либо релаксация спина ионов $\mathrm{Cu}^{+2}$ происходит нереально быстро. Даже если ширина линии ЭПР составляет 1000 Гс, тогда доля ионов $\mathrm{Cu}^{+2}$ составляет $<0.01 \%$. Таким образом, атомы меди в исследованных образцах $\mathrm{Sb}_{2-x} \mathrm{Cu}_{x} \mathrm{Te}_{3}(x=0,0.01,0.07,0.10)$ наиболее вероятно находятся в бесспиновом состоянии $\mathrm{Cu}^{+1}$.

\section{2. Термоэлектрические свойства}

В данной работе мы исследовали термоэлектрические свойства монокристаллов $\mathrm{Sb}_{2-x} \mathrm{Cu}_{x} \mathrm{Te}_{3}(x=0,0.01,0.07$, $0.10)$. На рис. 1, $a$ приведены температурные зависимости коэффициента Зеебека $\mathrm{S}$ для монокристаллов образцов $\mathrm{Sb}_{2-x} \mathrm{Cu}_{x} \mathrm{Te}_{3}$. Коэффициент Зеебека $\mathrm{S}$ - положительный, поскольку кристаллы имеют проводимость p-типа. Видно, что с понижением температуры значение $\mathrm{S}$ уменьшается. Наибольшее значение величина $\mathrm{S}$
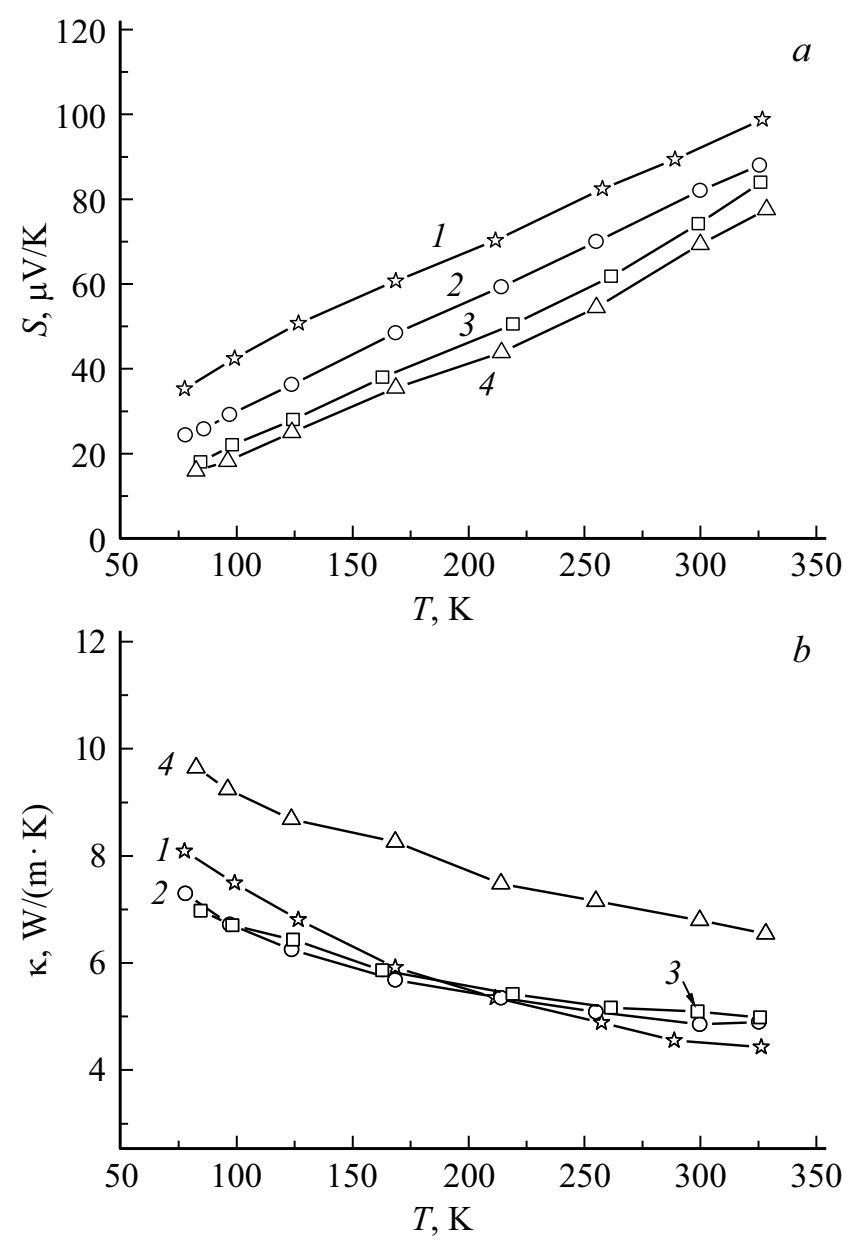

Рис. 1. Температурные зависимости: $a-$ термоэдс $\mathrm{S}, b-$ теплопроводности $\kappa$ для монокристаллов $\mathrm{Sb}_{2-x} \mathrm{Cu}_{x} \mathrm{Te}_{3}$ с различными $x(1-0,2-0.01,3-0.07,4-0.10)$. 

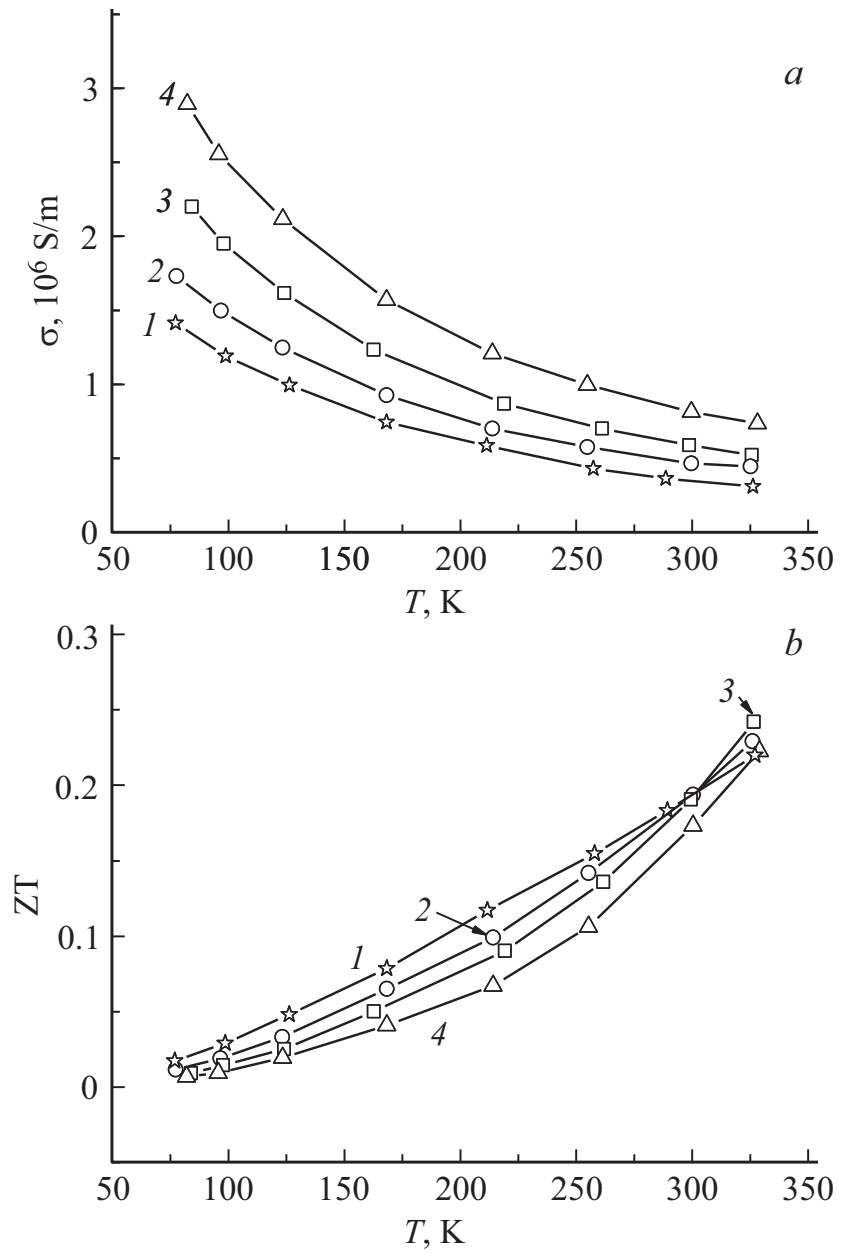

Рис. 2. Температурные зависимости: $a-$ проводимости $\sigma$, $b$ - безразмерной термоэлектрической эффективности ZT для монокристаллов $\mathrm{Sb}_{2-x} \mathrm{Cu}_{x} \mathrm{Te}_{3}$ с различными $x: 1-0,2-0.01$, $3-0.07,4-0.10$.

имеет выше комнатной температуры. С увеличением легирования медью коэффициент Зеебека уменьшается во всем интервале температур. График температурной зависимости теплопроводности $\kappa$ (рис. $1, b)$ показывает, что при легировании $\mathrm{Cu}$ теплопроводность $\kappa$ вблизи комнатной температуры практически не изменяется в $\mathrm{Sb}_{2-x} \mathrm{Cu}_{x} \mathrm{Te}_{3}$ вплоть до $x=0.07$. При снижении температуры ниже $150 \mathrm{~K}$ значение $\kappa$ становится даже меньше, чем в нелегированном образце. Такое поведение объясняется тем, что рассеяние фононов на примесях (с одной стороны) уже играет важную роль в этом легированном медью образце при низких температурах, что снижает теплопроводность решетки. С другой стороны, концентрация носителей заряда увеличивается, что вносит больший вклад в электронную теплопроводность. Эти два процесса приводят к такой зависимости $\kappa(T)$. С увеличением легирования до $x=0.10$ концентрация носителей заряда становится большой, и электронная роль играет существенную роль в теплопроводности, что приводит к увеличению значения $\kappa$ в образце с $x=0.10$. На рис. 2, $a$ приведены температурные зависимости электропроводности $\sigma$ в образцах монокристалла $\mathrm{Sb}_{2-x} \mathrm{Cu}_{x} \mathrm{Te}_{3}$. При измерениях учитывался эффект Пельтье, который возникает в термоэлектрических материалах при прохождении тока и изменении кажущегося сопротивления. Графики показывают, что, во-первых, проводимость сильно возрастает при легировании, и, во-вторых, с понижением температуры проводимость увеличивается во всех образцах. Металлический тип зависимости $\sigma(T)$ связан с высокой концентрацией дырок и вырождением энергетического спектра. Как видно из рис. 2, a, построенного в логарифмическом масштабе, преобладает рассеяние на фононах. На рис. 2, $b$ приведена температурная зависимость безразмерной термоэлектрической эффективности ZT, которая рассчитана по данным трех предыдущих графиков. Значения ZT увеличиваются с температурой, достигая $\sim 0.22$ при $T=325 \mathrm{~K}$ в чистом $\mathrm{Sb}_{2} \mathrm{Te}_{3}$. Легирование медью приводит к увеличению ZT при температуре $330 \mathrm{~K}$ до 0.24 при $x=0.07$. Если вспомнить, что $\mathrm{ZT}=\mathrm{S}^{2} \sigma T / \kappa$, становится ясно, что причина увеличения термоэлектрической эффективности заключается в сильном увеличении проводимости $\sigma$ (см. рис. $2, b)$ с небольшим уменьшением термоэдс $\mathrm{S}$ (см. рис. 2, $a$ ) и относительно незначительным увеличением теплопроводности $\kappa$ (см. рис. $2, b)$ при $x<0.07$.

\section{3. Квантовая подвижность дырок В $\mathrm{Sb}_{2-x} \mathrm{Cu}_{x} \mathrm{Te}_{3}$}

Зонная структура кристаллов $\mathrm{Sb}_{2} \mathrm{Te}_{3}$ имеет две зоны проводимости (нижняя зона проводимости $1-\mathrm{LCB}$ и верхняя зона проводимости $2-\mathrm{UCB}$ ) и две валентные зоны (зона легких дырок 3 - LHB и зона тяжелых дырок 4 - ННВ), как это показано на рис. 3 [5]. Кроме того, поверхностные состояния дают конус Дирака в спектре. Обе валентные зоны в $\mathrm{Sb}_{2} \mathrm{Te}_{3}$ имеют по 6 эллипсоидов поверхности Ферми, которые центрированы в плоскости симметрии.

Во всех образцах наблюдался эффект Шубниковаде Гааза, который дал возможность рассчитать энергию Ферми $E_{\mathrm{F}}$ дырок, концентрацию легких дырок PSdH и квантовую подвижность $\mu_{q}$ дырок в зависимости от

Таблица 1. Частота осцилляций Шубникова-де Гааза $F$, энергия Ферми $E_{\mathrm{F}}$, концентрация легких дырок $P_{\mathrm{SdH}}$ и квантовая подвижность $\mu_{q}$ для $\mathrm{Sb}_{2-x} \mathrm{Cu}_{x} \mathrm{Te}_{3}[6,7]$

\begin{tabular}{c|c|c|c|c|c}
\hline $\begin{array}{c}\mathrm{N} \\
\text { П.П. }\end{array}$ & Состав & $\begin{array}{c}F, \\
\mathrm{~T}\end{array}$ & $\begin{array}{c}E_{\mathrm{F}}, \\
\text { мэB }\end{array}$ & $\begin{array}{c}P_{\mathrm{SdH}}, \\
10^{19} \mathrm{~cm}^{-3}\end{array}$ & $\begin{array}{c}\mu_{\mathrm{q}}, \\
\mathrm{cm}^{2} /(\mathrm{B} \cdot \mathrm{c})\end{array}$ \\
\hline 1 & $\mathrm{Sb}_{2} \mathrm{Te}_{3}$ & 54.0 & 103.4 & 3.39 & 1100 \\
2 & $\mathrm{Sb}_{1.99} \mathrm{Cu}_{0.01} \mathrm{Te}_{3}$ & 73.6 & 139.4 & 5.31 & 890 \\
3 & $\mathrm{Sb}_{1.97} \mathrm{Cu}_{0.03} \mathrm{Te}_{3}$ & 78.3 & 148.3 & 5.83 & 1050 \\
4 & $\mathrm{Sb}_{1.95} \mathrm{Cu}_{0.05} \mathrm{Te}_{3}$ & 79.0 & 149.6 & 5.90 & 860 \\
5 & $\mathrm{Sb}_{1.93} \mathrm{Cu}_{0.07} \mathrm{Te}_{3}$ & 84.0 & 159.1 & 6.47 & 1000 \\
6 & $\mathrm{Sb}_{1.90} \mathrm{Cu}_{0.10} \mathrm{Te}_{3}$ & 134.3 & 254.4 & 13.09 & 630
\end{tabular}




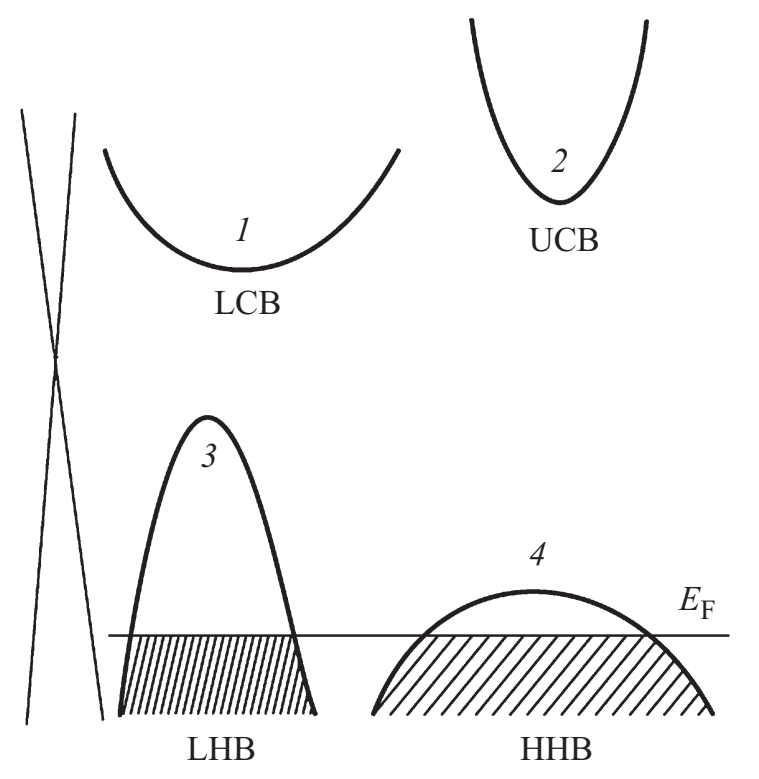

Рис. 3. Схематическая зонная структура $\mathrm{Sb}_{2} \mathrm{Te}_{3}$ около уровня Ферми $E_{\mathrm{F}}: 1$ - нижняя зона проводимости (LCB), 2 - верхняя зона проводимости (UCB), 3 - зона легких дырок (LHB), 4 - зона тяжелых дырок (HНB); в левой части показан спектр поверхностных состояний.

величины $x$ в $\mathrm{Sb}_{2-x} \mathrm{Cu}_{x} \mathrm{Te}_{3}$ [6,7]. Эти величины для исследованных в данной работе образцов приведены в табл. 1.

Как хорошо видно из таблицы, медь оказывает сильное акцепторное действие, концентрация дырок заметно увеличивается при легировании медью теллурида сурьмы. Кроме того, мы рассчитали по экспериментальным данным так называемую квантовую подвижность дырок $\mu_{\mathrm{q}}$. При определении подвижности электронов необходимо различать транспортное время релаксации и квантовое время релаксации [8-12]. Транспортное время релаксации импульса электрона $\tau_{t}$ определяется средним временем между упругими рассеяниями на примесях, существенно меняющими направление импульса, и может быть записано в виде

$$
\frac{1}{\tau_{t}}=\int_{0}^{\pi} \sigma(\varphi)(1-\cos \varphi) d \varphi,
$$

где величина $\sigma(\varphi)$ пропорциональна вероятности рассеяния в единицу времени на угол $\varphi$. Квантовое время релаксации $\tau_{q}$ (время одночастичной релаксации) получается путем усреднения времени между любыми событиями рассеяния и определяется выражением

$$
\frac{1}{\tau_{q}}=\int_{0}^{\pi} \sigma(\varphi) d \varphi
$$

Из-за множителя $(1-\cos \varphi)$ в выражении для $\tau_{t}$ транспортное время релаксации может отличаться от квантового. Для изотропного рассеяния, например, на фононах, эти времена рассеяния равны. Однако для кулоновского рассеяния на ионизированных примесях $\sigma(\varphi)$ велико для рассеяния на малых углах. Следовательно, $\tau_{t}$ может быть в несколько раз больше, чем $\tau_{q}$. Анализ зависимости амплитуды колебаний $\mathrm{SdH}$ от магнитного поля позволяет определить квантовые подвижности электронов $\mu_{q}=\frac{e}{m^{*}} \tau_{q}[9]$. Амплитуда осцилляций ШДГ экспоненциально зависит от квантовой подвижности [10,13-16]:

$$
\begin{aligned}
\Delta R_{x x}= & A \sum_{s=1}^{\infty} \exp \left(-\frac{\pi s}{\mu_{q} B}\right) \cos \left[\frac{2 \pi s E_{\mathrm{F}}}{\hbar \omega_{c}}-s \pi\right] \\
& \times \frac{\left(2 \pi^{2} s k_{\mathrm{B}} \tau / \hbar \omega_{c}\right)}{\sin h\left(2 \pi^{2} s k_{\mathrm{B}} \tau / \hbar \omega_{c}\right)} .
\end{aligned}
$$

Здесь $\omega_{c}-$ циклотронная частота, $B-$ индукция магнитного поля, $k_{\mathrm{B}}-$ константа Больцмана, $T-$ температура.

\section{4. Образцы $\mathrm{Sb}_{2-x} \mathrm{Sn}_{x} \mathrm{Te}_{3}$}

Для сравнения квантовых подвижностей при легировании различными примесями были также измерены квантовые подвижности дырок в монокристаллах $\mathrm{Sb}_{2-x} \mathrm{Sn}_{x} \mathrm{Te}_{3}$.

Осцилляции Шубникова-де Гааза в образцах наблюдались при температуре $1.3 \mathrm{~K}$ при направлении вектора магнитного поля вдоль оси $\mathrm{C}_{3}$ в магнитных полях напряженностью до 54 Тл. Осцилляции поперечного магнетосопротивления $\rho$ для кристаллов $\mathrm{Sb}_{2-y} \mathrm{Sn}_{y} \mathrm{Te}_{3}$ представлены на рис. 4, а их фурье-спектры - на вставке к рис. 4. Из рис. 4 видно, что в этих кристаллах наблюдается одна частота осцилляций, соответствующая верхней валентной зоне легких дырок. Отсутствие осцилляций от нижней валентной зоны связано с более высокими значениями эффективной массы в этой зоне, и для них не выполняются условия квантования.

В табл. 2 приведены данные по холловской концентрации, которая рассчитывалась как $1 / e R_{\mathrm{H}}$, где $e-$ заряд электрона, $R_{\mathrm{H}}$ - коэффициент Холла, холловской подвижности $\mu_{\mathrm{H}}$, а также частоты осцилляций $f$, рассчитанные по частотам энергии Ферми $E_{\mathrm{F}}$ и концентрации легких дырок $p_{\mathrm{SdH}}$.

Как видно из табл. 2, холловская концентрация дырок при легировании Sn возрастает, возрастает также частота осцилляций ШдГ, т.е. Sn имеет акцепторный эффект. Для определения концентрации легких дырок и энергии Ферми $E_{\mathrm{F}}$ использовался эффект Шубникова-де Гааза, методика расчета опубликована в [5-7]. Полуширина $\Delta f$ пика Фурье для образца $\mathrm{Sb}_{2} \mathrm{Te}_{3}$ показана на вставке рис. 4. Квантовые подвижности носителей заряда $\mu_{q}$, определенные по формуле (6), как функции содержания $\mathrm{Cu}$ приведены в табл. 1.

\section{5. Образцы $\mathrm{Sb}_{2-x} \mathrm{Tl}_{x} \mathrm{Te}_{3}$}

В ходе работы исследовались легированные таллием монокристаллы $\mathrm{Sb}_{2-x} \mathrm{Tl}_{x} \mathrm{Te}_{3}(x=0.0,0.005,0.015,0.05)$. 
Таблица 2. Параметры образцов $\mathrm{Sb}_{2-x} \mathrm{Sn}_{x} \mathrm{Te}_{3}$

\begin{tabular}{c|c|c|c|c|c|c|c|c}
\hline $\begin{array}{c}\mathrm{N} \\
\text { п.П. }\end{array}$ & Состав & $x$ & $\begin{array}{c}1 / e R_{\mathrm{H}}, \\
10^{19} \mathrm{~cm}^{-3}\end{array}$ & $\begin{array}{c}\mu_{\mathrm{H},}, \\
\mathrm{cm}^{2} /(\mathrm{B} \cdot \mathrm{c})\end{array}$ & $\begin{array}{c}f, \\
\text { Тл }\end{array}$ & $\begin{array}{c}E_{\mathrm{F}}, \\
\mathrm{MэB}\end{array}$ & $\begin{array}{c}p_{\mathrm{SdH},} \\
10^{19} \mathrm{~cm}^{-3}\end{array}$ & $\begin{array}{c}\mu_{q} \\
\mathrm{~cm}^{2} /(\mathrm{B} \cdot \mathrm{c})\end{array}$ \\
\hline 1 & & 0 & 8.16 & 1960 & 54 & 103.4 & 3.4 & 1100 \\
2 & \multirow{2}{*}{$\mathrm{Sb}_{2-x} \mathrm{Sn}_{x} \mathrm{Te}_{3}$} & 0.005 & 15.5 & 880 & 68 & 129.6 & 4.8 & 560 \\
3 & & 0.0075 & 17.2 & 690 & 76 & 144 & 5.6 & 700 \\
4 & & 0.010 & 27.0 & 400 & 97 & 183.6 & 8 & 390
\end{tabular}

Во всех образцах наблюдались осцилляции ШдГ, которые приведены на рис. 5, их фурье-спектры приводятся на вставке рис. 4. Все измерения, как уже говорилось, были проведены для ориентации магнитного поля вдоль оси $\mathrm{C}_{3}$. В этом случае для шестиэллипсоидной поверхно-

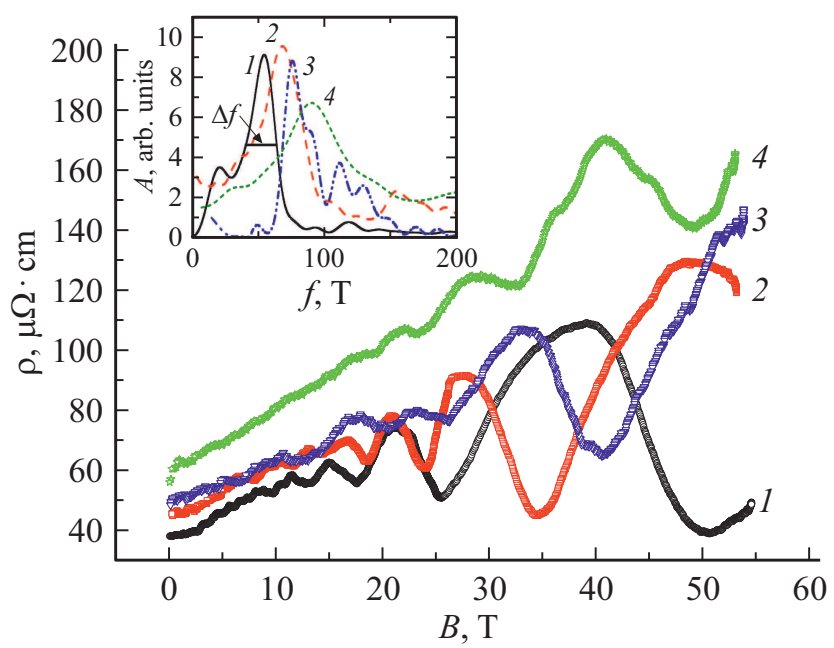

Рис. 4. Осцилляции поперечного магнетосопротивления $\rho$ для образцов $\mathrm{Sb}_{2-y} \mathrm{Sn}_{y} \mathrm{Te}_{3}$. На вставке - фурье-спектры осцилляций для 4 образцов $\mathrm{Sb}_{2-y} \mathrm{Sn}_{y} \mathrm{Te}_{3}$. Нумерация соответствует табл. 2.

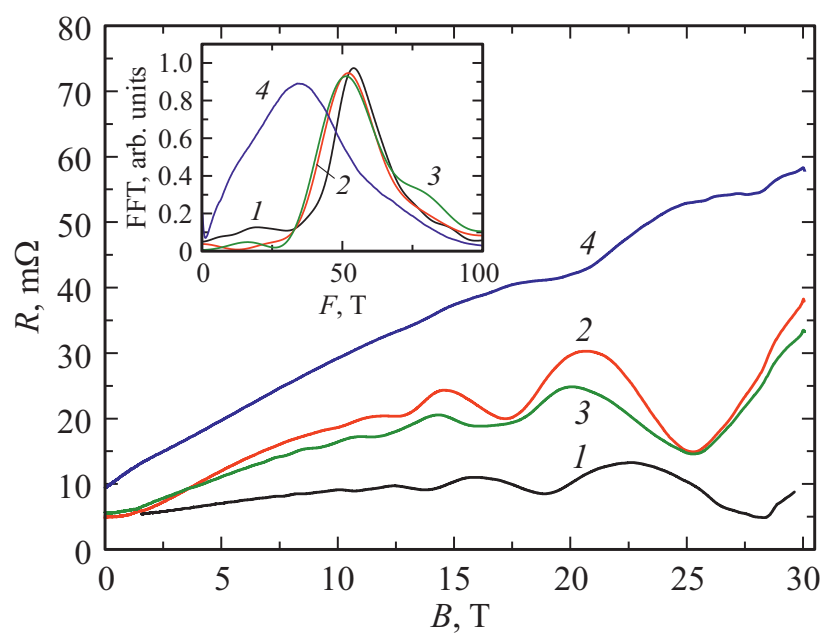

Рис. 5. Осцилляции Шубникова-де Гааза для $\mathrm{Sb}_{2-x} \mathrm{Tl}_{x} \mathrm{Te}_{3}$. На вставке - фурье-анализ осцилляций Шубникова-де Гааза для $\mathrm{Sb}_{2-x} \mathrm{Tl}_{x} \mathrm{Te}_{3}$. Нумерация соответствует табл. 3 .
Таблица 3. Параметры образцов $\mathrm{Sb}_{2-x} \mathrm{Tl}_{x} \mathrm{Te}_{3}$

\begin{tabular}{c|c|c|c|c|c}
\hline $\begin{array}{c}\text { № } \\
\text { П.П. }\end{array}$ & Состав & $\begin{array}{c}f, \\
\text { Тл }\end{array}$ & $\begin{array}{c}E_{\mathrm{F}}, \\
\text { мэB }\end{array}$ & $\begin{array}{c}p_{\text {SdH }}, \\
10^{19} \mathrm{~cm}^{-3}\end{array}$ & $\begin{array}{c}\mu_{q}, \\
\mathrm{~cm}^{2} /(\mathrm{B} \cdot \mathrm{c})\end{array}$ \\
\hline 1 & $\mathrm{Sb}_{2} \mathrm{Te}_{3}$ & 54 & 103.4 & 3.4 & 1100 \\
2 & $\mathrm{Sb}_{1.995} \mathrm{Tl}_{0.005} \mathrm{Te}_{3}$ & 52.1 & 93.7 & 2.7 & 790 \\
3 & $\mathrm{Sb}_{1.985} \mathrm{Tl}_{0.015} \mathrm{Te}_{3}$ & 51.3 & 92.2 & 2.6 & 760 \\
4 & $\mathrm{Sb}_{0.95} \mathrm{Tl}_{0.05} \mathrm{Te}_{3}$ & 34 & 61.1 & 1.4 & 420
\end{tabular}

сти Ферми легких дырок все сечения эллипсоидов совпадают, и наблюдается только одна частота осцилляций, что и видно на рис. 5.

Частота осцилляций уменьшается при увеличении легирования $\mathrm{Tl}$, что соответствует уменьшению концентрации легких дырок и энергии Ферми, т. е. Т1 проявляет донорные свойства в теллуриде сурьмы.

Аналогично тому, как это было сделано для образцов $\mathrm{Sb}_{2-y} \mathrm{Sn}_{y} \mathrm{Te}_{3}$, по частотам осцилляций рассчитывалась концентрация дырок и электронов и их энергии Ферми. В табл. 3 приведены некоторые параметры исследованных образцов, а именно частота осцилляций Шубникова-де Гааза $(f)$, энергия Ферми $\left(E_{\mathrm{F}}\right)$, концентрация легких дырок $p_{\mathrm{SdH}}$, а также квантовые подвижности носителей заряда $\mu_{q}$.

Формула (4) получена в приближении, что температура намного ниже, чем температура Дингла $T_{\mathrm{D}}=\frac{e \hbar}{2 \pi k_{\mathrm{B}}} \frac{1}{m_{c}^{*} \mu_{q}}$, и поэтому последний фактор в формуле (4), содержащий температуру, равен 1/2. Для исследуемых образцов это условие выполняется, так как температура равна $4.2 \mathrm{~K}$, а для $p-\mathrm{Sb}_{2-x} \mathrm{Cu}_{x} \mathrm{Te}_{3}$ циклотронная масса дырок в верхней зоне равна $m_{c}^{*}=0.083 m_{0}$ [17], а температура Дингла равна $45-124$ К. Следует отметить, что для легированного таллием $\mathrm{Sb}_{2} \mathrm{Te}_{3}$ подвижности дырок падают более чем в 3 раза при вдвое меньшей концентрации $\mathrm{Tl}$ по сравнению с $\mathrm{Cu}$. Таким образом, ионы $\mathrm{Cu}$ не сильно увеличивают рассеяние по сравнению с другими примесями.

Анализ полученных данных показывает, что квантовая подвижность в образцах $\mathrm{Sb}_{2} \mathrm{Te}_{3}$ почти в 2 раза ниже по сравнению с холловской. Это соответствует существенному вкладу рассеяния на заряженных точечных дефектах, характерных для теллурида сурьмы. При максимальном уровне легирования оловом $(x=0.01)$ квантовая подвижность $\mu_{q}$ уменьшается в $\sim 2.8$ раза. Для образцов 
$\mathrm{Sb}_{2-x} \mathrm{Tl}_{x} \mathrm{Te}_{3}$ при легировании до $x=0.05$, т.е. в 5 раз больше, чем в $\mathrm{Sb}_{2-x} \mathrm{Sn}_{x} \mathrm{Te}_{3}$, величина подвижности $\mu_{q}$ уменьшается в 2.8 раза, что сравнимо с предыдущим случаем. Наиболее интересно легирование $\mathrm{Cu}$. При легировании в 10 раз большем, чем оловом, и в 2 раза большем, чем таллием, подвижность $\mu_{q}$ уменьшается менее чем в 2 раза. Это показывает большую перспективность использования меди для изменения концентрации дырок в теллуриде сурьмы без существенного изменения подвижности, что важно для практических применений, например, в термоэлектричестве.

\section{4. Заключение}

Таким образом, замена сурьмы на медь оказывает акцепторный эффект в теллуриде сурьмы. По данным ЭПР, атомы меди в исследованных образцах, скорее всего, находятся в бесспиновом состоянии $\mathrm{Cu}^{+1}$. Легирование $\mathrm{Sb}_{2} \mathrm{Te}_{3}$ медью практически не изменило механизм рассеяния носителей, близкий к рассеянию на фононах при $T>100 \mathrm{~K}$, т.е. ионы $\mathrm{Cu}$ не сильно увеличивают рассеяние по сравнению с другими примесями, например оловом. Электропроводность сильно возрастает при легировании $\mathrm{Cu}$, термоэдс немного уменьшается, теплопроводность увеличивается только при максимальном содержании $\mathrm{Cu}$. Это приводит к росту термоэлектрической эффективности при легировании $\mathrm{Sb}_{2} \mathrm{Te}_{3}$ медью при $T>300 \mathrm{~K}$.

\section{Конфликт интересов}

Авторы заявляют, что у них нет конфликта интересов.

\section{Список литературы}

[1] H. Scherrer, S. Scherrer. 2006 Macro to Nano Handbook, ed. by D.M. Rowe (CRC Press, Taylor \& Francis Group).

[2] G.J. Snyder, E.S. Toberer. Nature Materials, 7, 105 (2008).

[3] В.А. Кульбачинский, А.А. Кудряшов, В.Г. Кытин. ФТП, 49, 786 (2015).

[4] П.М. Тарасов, В.А. Кульбачинский, В.Г. Кытин. ЖЭТФ, 132, 31 (2007).

[5] V.A. Kulbachinskii, D.A. Zinoviev, V.G. Kytin, M.K. Mikhailov, Zh.T. Ismailov. Materials Today: Proceedings, 44, 3439 (2021).

[6] В.А. Кульбачинский, Д.А. Зиновьев, Н.В. Маслов, В.Г. Кытин. ЖЭТФ, 155, 1091 (2019).

[7] Ж.Т. Исмаилов, В.А. Кульбачинский. Bull. Karaganda University. „Physics“ ser., № 1(97), 26 (2020).

[8] P.M. Koenraad. In: Delta Doping of Semiconductors, ed. by E.F. Schubert (Cambridge University Press, Cambridge, 1996) chap. 17.

[9] P.M. Koenraad, A.F.W. van de Stadt, J.M. Shi, G.Q. Hai, J.H. Wolter. Physica B, 211, 462 (1995).

[10] P.T. Coleridge, R. Stoner, R. Fletcher. Phys. Rev. B, 39, 1120 (1989).
[11] В.А. Кульбачинский, В.Г. Кытин, Р.А. Лунин, В.Г. Мокеров, А.П. Сеничкин, А.С. Бугаев, А.Л. Карузский, А.В. Пересторонин, R.T.F. van Schaijk, A. de Visser. ФТП, 33, 839 (1999).

[12] В.А. Кульбачинский, Л.Н. Овешников, Р.А. Лунин, Н.А. Юзеева, Г.Б. Галиев, Е.А. Климов, С.С. Пушкарев, П.П. Мальцев. ФТП, 49, 942 (2015).

[13] A. Isihara, L. Smrcka. J. Phys. C: Solid State Phys., 19, 6777 (1986).

[14] В.А. Кульбачинский, Р.А. Лунин, Н.А. Юзеева, И.С. Васильевский, Г.Б. Галиев, Е.А. Климов. ФТП, 47, 927 (2013).

[15] В.А. Кульбачинский, Р.А. Лунин, Н.А. Юзеева, И.С. Васильевский, Г.Б. Галиев, Е.А. Климов. ЖЭТФ, 143, 872 (2013).

[16] В.А. Кульбачинский, Л.Н. Овешников, Р.А. Лунин, Н.А. Юзеева, Г.Б. Галиев, Е.А. Климов, П.П. Мальцев. ФТП, 49, 204 (2015).

[17] V.A. Kulbachinskii, N. Miura, H. Arimoto, T. Ikaida, P. Lostak, H. Horak, C. Drasar. J. Phys. Soc. Jap., 68, 3328 (1999).

\section{Thermoelectric figure of merit and quantum mobility of holes in single crystals of antimony telluride doped with copper}

\author{
V.A. Kulbachinskii ${ }^{1,2,3}$, V.G. Kytin ${ }^{1}$, A.S. Apreleva ${ }^{1}$, \\ E.A. Konstantinova ${ }^{1}$
}

${ }^{1}$ Lomonosov Moscow State University,

Low Temperature Physics and

Superconductivity Department, 119991 GSP-1, Moscow, Russia

${ }^{2}$ Moscow Institute of Physics and Technology, 141700 Dolgoprudny, Moscow Region, Russia

${ }^{3} \mathrm{NRC}$ „Kurchatov Institute", 123182 Moscow, Russia

Abstract We report the results of a study of thermoelectric properties in the temperature range $77<T<350 \mathrm{~K}$ of singlecrystal $\mathrm{Sb}_{2-x} \mathrm{Cu}_{x} \mathrm{Te}_{3}(0 \leq x \leq 0.10)$ samples synthesized by the Bridgman method. It turned out that the hole concentration and conductivity increase strongly, and the Seebeck coefficient insignificantly decreases when $\mathrm{Sb}_{2} \mathrm{Te}_{3}$ is doped with copper. The thermal conductivity of the samples doped with $\mathrm{Cu}$ is slightly higher than that of the initial $\mathrm{Sb}_{2} \mathrm{Te}_{3}$. As a result, the thermoelectric figure of merit $Z T$ increases with an increase in the $\mathrm{Cu}$ content at $T>300 \mathrm{~K}$. In addition, the results of measurements of the quantum mobility of holes $\mu_{q}$ from data on the Shubnikov - de Haas ( $\mathrm{SdH})$ effect in in single crystals of $\mathrm{Sb}_{2-x} \mathrm{Cu}_{x} \mathrm{Te}_{3}(0 \leq x \leq 0.10), \mathrm{Sb}_{2-x} \mathrm{Sn}_{x} \mathrm{Te}_{3}(0 \leq x \leq 0.01)$ and $\mathrm{Sb}_{2-x} \mathrm{Tl}_{x} \mathrm{Te}_{3}(0 \leq x \leq 0.05)$ are given. EPR measurements show that copper atoms in the studied samples are most likely in the $\mathrm{Cu}^{+1}$ spinless state. 